University of Massachusetts Amherst

ScholarWorks@UMass Amherst

2014

\title{
Social Hierarchies and Public Distribution of Food in Rural India
}

\author{
Deepankar Basu \\ University of Massachusetts - Amherst \\ Debarshi Das \\ Indian Institute of Technology - Guwahati
}

Follow this and additional works at: https://scholarworks.umass.edu/econ_workingpaper

Part of the Economics Commons

\section{Recommended Citation}

Basu, Deepankar and Das, Debarshi, "Social Hierarchies and Public Distribution of Food in Rural India" (2014). Economics Department Working Paper Series. 170.

https://doi.org/10.7275/6031782

This Article is brought to you for free and open access by the Economics at ScholarWorks@UMass Amherst. It has been accepted for inclusion in Economics Department Working Paper Series by an authorized administrator of ScholarWorks@UMass Amherst. For more information, please contact scholarworks@library.umass.edu. 


\section{DEPARTMENT OF ECONOMICS}

Working Paper

Social Hierarchies and Public Distribution of Food in Rural India

by

Deepankar Basu

Debarshi Das

Working Paper 2014-05

\section{UNIVERSITY OF MASSACHUSETTS AMHERST}




\title{
Social Hierarchies and Public Distribution of Food in Rural India $¥$
}

\author{
Deepankar Basu! and Debarshi Das*
}

\begin{abstract}
In this paper, we develop a simple model that shows that consumption of PDS food grains is significantly different between rich and poor households in states where the PDS functions relatively well; in places where the PDS is non-functional, the difference is not significant. Using household-level data from three recent thick rounds of the consumption expenditure survey (2004-2005, 2009-2010 and 2011-2012), we find evidence in support of the predictions from the model. This suggests that one way to make the PDS functional is to make it more accessible to poor and underprivileged households.
\end{abstract}

Keywords: public distribution system; India; development policy; food security JEL Codes: O2; I38

\section{Introduction}

In India, the Public Distribution System (PDS) started in a nebulous state during the Second World War. Its purpose was to make essential food items available to residents of selected urban centres at a time of acute war time shortage. After independence of the country in 1947, the ambit of the programme was expanded, with a special push in the mid-1960s (Swaminathan, 2001). This is hardly surprising once it is recalled that the mid-1960s was, once again, a time of bad harvests, shooting food prices, and political turmoil. Himanshu and Sen (2013a) point out that the stated purpose of the system has been to ensure availability of food at affordable price at

\footnotetext{
${ }^{\ddagger}$ We would like to thank Jim Boyce, Anirban Kar, Kartik Mishra, Riko Rosette, and other participants at the seminar in the Department of Economics, University of Massachusetts, Amherst for useful comments. The usual disclaimers apply.

' Department of Economics, University of Massachusetts, Amherst, USA. Email: dbasu@econs.umass.edu

* Department of Humanities and Social Sciences, Indian Institute of Technology, Guwahati, India. Email: debarshidas@iitg.ernet.in
} 
times of distress and enhancing nutritional intake through access of food. ${ }^{1}$ Furthermore, over time farmers have also become beneficiaries of the system. For instance, about $20 \%$ of the subsidies for purchase and distribution of cereals accrue to farmers (Himanshu and Sen, 2013a). This is because the grains that are meant to be distributed to consumers through the PDS are first purchased from farmers at a price - called the Minimum Support Price (MSP) - that is often above the post-harvest open market price.

The scale of operation and reach of the PDS has expanded over the years. In 2011-2012 about 45.6\% of the Indian population, which translates to 552 million people, purchased some PDS rice or wheat; in 1993-1994, the corresponding proportion was only 24.1\%. Average consumption of grains (rice and wheat) increased from 4.58 kilograms per household per month in 1993-1994 to 9.56 kilograms per household per month in 2011-2012. While rice and wheat remain the mainstay of the PDS, other cereals, kerosene, sugar and other food items are also distributed.

The operation of the PDS depends on the interplay of policies at the central and state levels. The central government procures certain food items, for instance rice and wheat, from farmers through the Food Corporation of India (FCI) and holds them in the FCI storage facilities. Depending on pre-determined number of beneficiaries in different states under various welfare schemes and past utilisation of PDS food grains by the states, food grains are then allocated to the states. The state governments, in turn, are free to modify the central allocation by including more items for distribution, or by augmenting the quantity of an item, or by changing the issue price to be paid by beneficiaries.

\footnotetext{
${ }^{1}$ Swaminathan (2008) noted some additional objectives like control over private trade and price stability.
} 
However, the PDS has always had its detractors, who have emphasised the problem of corruption and leakage. A common measure of corruption in the system is called "diversion", which is the proportion of food grains collected by states from the central pool (allocated for various welfare schemes) that does not reach the intended beneficiaries. Data on central allocation (and offtake) for all states are available from the Foodgrain Bulletin of the Ministry of Food and Consumption Affairs, Government of India; actual consumption of PDS food grains can be calculated from household-level data collected as part of the consumption expenditure survey (CES) conducted by the National Sample Survey Organisation (NSSO). The gap between offtake and actual consumption is the amount lost. Dividing this by the offtake figure provides an estimate of diversion.

In 2004-2005, diversion for rice and wheat was about 54\%, so that more than half of the rice and wheat released by the central government for the PDS did not reach the beneficiaries (Khera, 2011b). Surely, a part of the diversion could be due to spoilage, losses during transportation and other incidental losses. But corruption appears to be a major flaw bleeding the system. In terms of temporal evolution, diversion has declined over the recent past: from 54\% in 2004-05, it came down to 39.9\% in 2009-2010, and then fell further down to 34.6\% in 2011-2012 (Himanshu and Sen, 2013a). ${ }^{2}$ However, if close to or more than one-third of the food grains sent for the PDS gets stolen, the system can hardly be considered to be functioning well.

\footnotetext{
${ }^{2}$ Our own calculations suggest that diversion in 2011-2012 is a little lower at 29.43\% (see the last column in Table $1)$.
} 
Critics have called for a radical change in the very mechanism of delivering food. For example, Kotwal et al. (2011) have advocated for dismantling of State procurement, transportation and distribution of food to the poor. Instead, they argue that the poor could be given cash entitlements (through biometric cards) to be redeemed with the purchase of food from a shop at market price. Since the shop owner gets the same amount of money whether she sells the grain to a PDS beneficiary or a non-beneficiary, there will be no incentive for diversion (assuming no extra transaction cost for PDS sale). This view essentially argues for (a) switching from in-kind to in-cash transfer to beneficiaries and (b) delinking procurement of grain from distribution of subsidised food. Such views are enormously influential, as evidenced by their acceptance in establishment circles. For instance, the National Food Security Bill passed by the Indian parliament in 2013 envisages "introducing schemes, such as, cash transfer, food coupons, or other schemes, to the targeted beneficiaries in lieu of their foodgrain entitlements..." (GOI, 2013). In fact, the high rate of diversion lends credence to the charge that the present system of in-kind transfer of food is inefficient and leaky and has to be replaced by a more market oriented mechanism built on cash transfers.

Critics of the in-cash alternative point out that it may not be workable given the limited reach of markets, banks, power and other infrastructural facilities across much of the Indian countryside. Moreover, the impact of an in-cash system on nutrition might be lower than the in-kind system. For instance, by estimating a calorie demand function Himanshu and Sen (2013b) have empirically compared the impact of in-kind transfer with the equivalent in-cash transfer on calorie intake. They found that even in the absence of leakage costs in the in-cash transfer system, the in-kind system fared better: "a PDS transfer equal to 1\% of out-of-pocket MPCE 
increases calorie intake by around twice as much as a $1 \%$ increase in out-of-pocket MPCE.” This strong result is noteworthy given that (a) there has been a disconcerting decline of calorie intake in recent years (Basu and Basole, 2014) and (b) an important aim of PDS has always been to enhance nutritional intake. However the econometric results in the paper suffer from some problems that the authors themselves note. For instance, while estimating the calorie demand function real monthly per capita expenditure (MPCE) is taken as an explanatory variable. It can be argued that calorie consumption and MPCE are jointly determined by the consumer. Hence it may be incorrect to posit the latter as a determinant of the former. Thus, the specification might suffer from problems of endogeneity.

In the present paper we seek to contribute to the discussion by exploring a different dimension of the problem. Although diversion figures are high and per household PDS consumption is low at the all-India level (these two are inversely related as we shall see later), the conditions are not uniformly dismal; there is a wide variation across states. Among the major states, Gujarat, Haryana, Punjab, and West Bengal had PDS consumption below the national average in 20112012 (see Table 1). On the other side, states like Andhra Pradesh, Himachal Pradesh, and Tamil Nadu reported PDS consumption of rice and wheat much above the national average in 20112012. In fact, the division between states with well-functioning and non-functioning PDS has been relatively stable for the past several decades (we call the former "functioning states" and the latter "non-functioning states"). While states like Gujarat, Haryana, Punjab and West Bengal have consistently performed below average, in Andhra Pradesh, Tamil Nadu, and Himachal Pradesh the PDS has performed much better than for the country as a whole. Thus, these states have always reported low diversion and high PDS consumption figures. While earlier researchers 
have emphasised this distinction between states, there have also been attempts to understand the determinants of well-functioning PDS systems through detailed field studies in Rajasthan (Khera, 2011c).

[Table 1 about here]

In this paper we take a different route: we use variation among rural areas across states and over time to understand factors that make a PDS relatively well-functioning. Our key hypothesis is that one of the important dimensions of the distinction between functioning and non-functioning states hinges on the degree of access to the PDS for socially and economically marginalised households: in functioning states, marginalised households have greater access to the PDS than in non-functioning states. Consequently, marginalized households consume more than privileged households in functioning states, but their consumption levels do not differ much in nonfunctioning states.

To be sure, functioning states perform better compared to non-functioning states for reasons that cannot be attributed to ensuring access to PDS for marginalized sections. Pro-active identification of BPL families and distribution of ration cards have a bearing on performance as well. Other state-specific initiatives have played their part too. However, our focus in this paper is on the access to PDS for the marginalized and its effect on consumption of PDS food grains.

We test the hypothesis regarding differential PDS consumption between privileged and marginalized households in functioning and non-functioning states using household-level data 
from three recent most "thick" rounds of the Consumption Expenditure Survey (CES) conducted by the National Sample Survey Organisation (NSSO): $61^{\text {st }}$ round (2004-2005), 66 ${ }^{\text {th }}$ round (20092010) and $68^{\text {th }}$ round (2011-2012). We take account of marginalisation (or equivalently, hierarchy) along important economic and social dimensions: wealth (measured by quantity of operated land), class (measured by broad occupational categories), caste, religion, formal education, and gender. Our results show that in states where the PDS is functioning well (that is, where consumption from PDS is high and diversion is low), households at the bottom of social and economic hierarchies get higher amounts of food from the PDS compared to those higher up in the hierarchies. In stark contrast, non-functioning states do not show this egalitarian trend of PDS consumption.

While this paper is similar in spirit to Khera (2011a), we extend her analysis in two key respects: a more flexible specification of consumption and an investigation of the effects of socioeconomic hierarchies. First, we estimate a more flexible specification of the consumption of PDS food grains (rice and wheat taken together) by using the price of PDS food grains and the price of open market food grains as separate regressors, instead of using their difference as a regressor, as specified by Khera (2011a). ${ }^{3}$ In addition, we control for other social and economic characteristics of households such as schooling of household head, amount of land operated, occupation, caste, religion and so forth. We replicate and strengthen the key insight of Khera (2011a) regarding the response of PDS purchase to price changes by showing that PDS purchase does not increase monotonically with open market price (after controlling for PDS price and

\footnotetext{
${ }^{3}$ A specification with the difference between open market and PDS price of food grains as a regressor is a restricted version of a specification with the open market price and PDS price as separate regressors. This is because the former specification imposes the restriction that the coefficient on the two prices be identical in magnitude and opposite in sign.
} 
other household level determinants). Our results show that PDS purchase is an inverted-U function of open market price, so that at high values of open market price (holding PDS price constant), PDS consumption falls. This evidence rejects the hypothesis that consumption of PDS food is completely demand determined. Thus, we are left with the other possibility that purchase from PDS is constrained from the supply-side (because of diversion). Hence, access to the PDS becomes salient.

Second, we move beyond the analysis in Khera (2011a) by positing that access to the PDS is influenced by the structure of privileges entrenched in society. This leads us to explore the effect of social and economic hierarchies (wealth, occupation, caste, religion and gender) on PDS purchase. Results from our empirical analyses confirm our intuition: in well-functioning states, those at the bottom rungs of the ladder have greater access to PDS. Thus, this paper extends Khera’s (2011a) analysis by using interstate variation to tease out some important determinants of a well-functioning PDS.

It is worth noting that our analysis has focused on rural areas only. This follows from our understanding that social divisions are likely to be more rigid and marginalisation more pronounced in rural areas. Thus, supply-side constraints, working through and reinforcing socioeconomic hierarchies, are likely to pose greater challenges for the PDS in rural areas. If a state government, aided no doubt by grassroots mobilisation, is able to nullify the deleterious effects of these socio-economic hierarchies, a process of self-selection and local enforcement is likely to take shape. This would allow the less privileged sections to continue to avail of their PDS entitlements. As a result, relatively higher shares of PDS allocations would be distributed. Thus, 
one would observe low diversion and high PDS food grain consumption (per household) in these states. A simple but powerful conclusion emerges from our study: one of the important requirements of a functional PDS has to do with the easing of supply-side constraints, working through and reinforcing socio-economic hierarchies, for marginalised sections of society.

The rest of the paper is organised as follows. Section II develops a simple economic model of consumer behaviour that helps us understand the key issues involved in thinking about the functioning of PDS. Section III introduces the data and the econometric strategy that is used to test the implications of the model developed in the previous section. Section IV presents and discusses the results. The final section concludes the paper by noting some caveats and pointing towards possible future directions of work.

\section{A Simple Model}

In this section, we develop a rudimentary single period model of consumer decision making in a two commodity world. The two commodities are the two types of food grains that the consumer can choose from: $X$ (PDS food grain) and $Y$ (open market food grain).The consumer has a fixed amount of money income, $M$, to spend on food grains, and the prices of $X$ and $Y$ are given by $p_{x}$ and $p_{y}$ respectively, where $p_{y}>p_{x}$. Let $x$ and $y$ denote consumption levels of the two goods respectively. Let $q$ denote the maximum amount of $X$ that a consumer can buy from the fair price shop (FPS), i.e., $q$ is the official quota of PDS food grains. Her preference structure is as follows: she prefers $Y$ over $X$; and to fulfill her food requirements, the consumer wants to consume a minimum of $c$ units of food grains. 
The motivation for this specification of our model is simple. In the literature on the PDS, it is commonly understood that the rich (or the privileged) tend to opt out of PDS consumption. The reason has to do with the inferior quality of PDS food grains compared to the more expensive, and presumably higher quality, food grains available in the market (Balakrishnan and Ramaswami, 1997; Himanshu and Sen, 2011). In our model, we capture this by letting $X$ denote the PDS food grain and $Y$ the open market food grain. While $X$ is offered for sale through FPSs at a low price, $Y$ can only be purchased in the open market at a higher price $\left(p_{y}>p_{x}\right)$.

The primary focus of our model is to understand the differing consumption of PDS food grains by different sections of the population, with the latter defined in terms of economic and social hierarchies. The distinction between inferior quality PDS food grains and better quality open market food grains is therefore of salience here, unlike in Khera (2011a) where this distinction is not made. Note also in passing that inferiority may be defined in a broader sense than contained in the claim that PDS food grains are of inferior quality. For instance, there may be implicit costs involved in the purchase of PDS food (the trouble of visiting a fair price shop, which may not be selling the good at that time, or the compulsion of having to make a bulk purchase for a month and so forth), which may make it less attractive and hence inferior. From the above specification of preferences over the two commodities, $X$ and $Y$, the demand functions can be calculated as follows.

\section{Case 1: $c \cdot p_{x}>M$}

The consumer is extremely poor and cannot afford to fulfill the required minimum quantity of food grains even with the poor quality cheap grain only. 


\section{- Case 1(a):q. $p_{x} \leq M$}

Since she wants to consume a minimum quantity of grains, $c$, she will purchase the entire quota $q$ of $X$. With the rest of her income, $M-q \cdot p_{x}$ she purchases as much $Y$ as possible. Thus, $x^{*}=q$, and $y^{*}=\frac{M-q \cdot p_{x}}{p_{y}}$.

\section{- Case 1(b): $M<q . p_{x}$}

In this case her entire income is exhausted by consuming $X$. Hence, $x^{*}=\frac{M}{p_{x}}$, and $y^{*}=0$.

\section{Case 2: $M>c \cdot p_{y}$}

The consumer is rich enough to buy the better quality food grain, i.e., commodity $Y$. In this case, the consumption of $X$ would be zero, and the entire income would be spent on $Y$. Hence, $x^{*}=0$, and $y^{*}=\frac{M}{p_{y}}$.

\section{Case 3: $c . p_{y} \geq M \geq c \cdot p_{x}$}

In this case, the consumer may not be rich enough to meet her entire food requirement through purchasing $Y$ alone; but neither is she poor enough to be pushed to consuming $X$ alone. Thus, demands for $X$ and $Y$ are given by: $x^{*}=\frac{c \cdot p_{y-M}}{p_{y}-p_{x}}$, and $y^{*}=\frac{M-c \cdot p_{x}}{p_{y}-p_{x}}$.

To summarise, the rich consumer buys only $Y$. Thus, they are self-selecting themselves out of the PDS. The extremely poor consumer buys only $X$ (except for the case where PDS quota is less than the minimum food requirement and the consumer has money left after spending on the quota). For the poor (not extreme poor), the consumption basket includes both $X$ and $Y$. Note that 
if $c>x^{*}$, the poor do not exhaust the entire PDS quota and spend a part of the income on the more expensive market food. This last result is different from Khera (2011a).

It is important to note that $x^{*}$ is the demand for PDS food grains by the poor (the rich do not consume PDS food grains). But there is no guarantee that this would actually be realised. Our hypothesis is that the social and economic hierarchies operate in a manner which restricts the access of the marginalised to PDS. To see how this might operate, let $q_{a}$ denote the actual quota of PDS food grains for the socio-economically marginalised after different biases are taken into account. For instance, a dalit agricultural labour household might be given only half of the official quota by the owner of the fair price shop, with the rest sold off in the open market. Thus, if biases are strong, we will have the following: $q>q_{a}$. Hence, if for a poor household $x^{*}>q_{a}$, actual consumption gets determined by $q_{a}$ - and does not attain the unconstrained value of $x^{*}$ (the optimal choice). Thus, in this case, $x_{a}=q_{a}$, where $x_{a}$ denotes actual consumption.

Moreover, when bias against the marginalised is high $q_{a}$ might be pushed down to zero so that actual PDS consumption of the socio-economically marginalised household may become close to zero. Recall that the rich and privileged households have zero PDS consumption by choice. Thus, in states where bias is high, actual consumption levels of the privileged and the marginalised becomes numerically close (because both are close to zero), and the difference between the two is no longer significant. On the other hand, in states where the bias has been tamed to an extent, the marginalised will be relatively free to get their demanded quantity. Thus, 
$x_{a}$ will be close to $x^{*}$ and significantly different from the consumption of $X$ by the privileged (which is close to zero by choice). ${ }^{4}$ We summarise this key insight as

Proposition 1. In states with well-functioning PDS, consumption of PDS food grains by the rich and poor are significantly different; in states with non-functioning PDS, consumption of PDS food grains by the rich and poor are not significantly different.

It is also easy to understand why well-functioning states tend to remain so over long periods of time. Once a section of the people gets access to PDS benefits, it becomes difficult to take that away for fear of political backlash. A well-functioning PDS thus becomes self-sustaining. Thus, states like Andhra Pradesh, Himachal Pradesh and Tamil Nadu not only have well-functioning PDS today, where per household PDS consumption is high and diversion low; these are the states where the PDS has been functioning well for several decades. ${ }^{5}$

\section{Data and Econometric Methodology}

\section{III.1. Data}

To test the implications emerging from the economic model developed in Section II, we use household level data from the three recent-most "thick" rounds of the CES conducted by the NSSO: $61^{\text {st }}$ round (2004-2005), $66^{\text {th }}$ round (2009-2010) and $68^{\text {th }}$ round (2011-2012).The "thick" rounds of the CES are nationally representative sample surveys that collect detailed information about consumption expenditure behaviour of Indian households and household level

\footnotetext{
${ }^{4}$ Zero PDS consumption by the rich should be taken as an abstraction of the model. Instead of zero, it could be a positive quantity depending on the choice of the origin. What is of import is the convergence and divergence of consumption by the rich and poor under different conditions.

${ }^{5}$ There is an early support of this in Swaminathan (2000), based on a survey of four states: "in states with low coverage, such as Bihar and Uttar Pradesh, neither poor nor rich had access to the PDS. In states with high coverage, such as Kerala and to some extend Andhra Pradesh, the PDS was utilized more by the poor than by the rich.”
} 
characteristics like caste, religion, schooling and gender of household head. For items of consumption that are distributed through the PDS, the CES provides information on the quantity and value of purchase from the PDS and from the open market.

For the purpose of this study, we use information on PDS and open market consumption - both quantity and value - for rice and wheat. While we use information on the quantity of consumption directly, we divide the value of consumption by the quantity to compute the price paid by households. This allows us to separately compute the price paid by households for purchase (of rice and wheat) from the PDS and from the open market. Since there is likely to be lot of noise in the price data at the household level, we use the simple average of household-level prices at the state-region level for our analysis. ${ }^{6}$ In addition to data on PDS consumption and price, we also use data on household level characteristics and possession of Antyodaya and BPL (below poverty line) ration card. ${ }^{7}$

A key purpose of this paper is to use the difference in the effectiveness of the PDS in functioning and non-functioning states. To distinguish between these two groups of states, we follow the classification used by Khera (2011b). A state is categorised as a "functioning state" if average PDS consumption of food grains (rice and wheat) per capita has been more than $1 \mathrm{~kg} / \mathrm{month}$ in the decade of the 2000s; a state is categorised as a "non-functioning state" if PDS consumption of food grains (rice and wheat) per capita has been consistently below $1 \mathrm{~kg} /$ month over the same period. Using this criterion, Khera (2011b) constructed the two groups as follows:

\footnotetext{
${ }^{6}$ In NSSO surveys, each state is divided into several state-regions (some of the smaller states and union territories have one state-region) comprising of many districts. State-regions are the lowest level of aggregation at which NSS data is representative. Hence, we aggregate prices at the state-region and not at the level of districts.

${ }^{7}$ Antyodaya households are the poorest among the BPL households. They are entitled to higher benefits than ordinary BPL households.
} 
- Functioning States (NFS=0): Andhra Pradesh, Himachal Pradesh, Jammu \& Kashmir, Kerala, Karnataka, Maharashtra, Tamil Nadu;

- Non-functioning States (NFS=1): Assam, Bihar, Gujarat, Haryana, Jharkhand, Rajasthan, West Bengal, Punjab.

What we are calling "non-functioning states" is referred to as "languishing states" by Khera (2011b). She has a third category of states, "reforming states", which have shown improvement in PDS functioning over time; these states report average PDS food grain per capita consumption of roughly $1 \mathrm{~kg} /$ month. To clearly capture the difference between the two, in this study we restrict our sample to functioning and non-functioning states only. Thus, the final sample for our empirical analysis includes rural households for the seven functioning and eight non-functioning states at three different time periods: 2004-2005, 2009-2010 and 2011-2012.

Note that our definition of functioning and non-functioning states is consistent with various patterns of consumption by the privileged and non-privileged. For instance, the fact that functioning states have higher per capita PDS consumption can arise inter alia in either of the following two scenarios: (a) in functioning states consumption of PDS food grains is high but not significantly different for both privileged and under-privileged households; and (b) in functioning states consumption of PDS food grains is high for both privileged and underprivileged households, and under-privileged households consume significantly higher PDS food grains than the privileged. Our model points towards the second scenario - where the difference in the PDS consumption between the privileged and under-privileged is significantly different and we will test this with household level data from rural India. 
[Table 2 about here]

Table 2 provides summary statistics for the key variables used in this study for rural areas of the two groups of states. For functioning states, average household consumption of PDS food grains (rice and wheat) has increased from $11.17 \mathrm{~kg} /$ month in 2004-2005 to $14.5 \mathrm{~kg} / \mathrm{month}$; for nonfunctioning states, the increase is from $2.11 \mathrm{~kg} / \mathrm{month}$ in $2004-2005$ to $8.80 \mathrm{~kg} / \mathrm{month}$. Thus, non-functioning states started the period with a very low level of PDS consumption, but reported a sharper increase over the period of study. Reflecting some improvements in the functioning of the PDS, the difference in PDS consumption between the two groups of states has come down substantially over time: from $9.06 \mathrm{kgs} / \mathrm{month} /$ household to $5.7 \mathrm{kgs} / \mathrm{month} /$ household. Open market price and PDS price of food grains are generally higher in the functioning states (other than for the latter in 2009-2010), with the difference narrower for PDS price. Open market price has roughly doubled over the period of study, in functioning states from $11.78 \mathrm{Rs} / \mathrm{kg}$ to 21.83 Rs/kg and in non-functioning states from $9.65 \mathrm{Rs} / \mathrm{kg}$ to $17.36 \mathrm{Rs} / \mathrm{kg}$; but PDS price has declined slightly over this period, for functioning states from $5.39 \mathrm{Rs} / \mathrm{kg}$ to $5.17 \mathrm{Rs} / \mathrm{kg}$ and for nonfunctioning states from $5.31 \mathrm{Rs} / \mathrm{kg}$ to $5.25 \mathrm{Rs} / \mathrm{kg}$.

We see an important difference between the two groups of states with regard to the proportion of BPL-plus households, that is, households that possess either Antyodaya or BPL ration cards. The proportion of households with Antyodaya or BPL ration cards is an important indicator of the pro-active nature of state governments with regard to the PDS. While the central government allocates food grains to states on the basis of an estimate of the BPL population, it is the discretion of individual states to identify BPL-plus households and distribute ration cards. Thus, 
pro-active states that want to increase the reach of the PDS might distribute Antyodaya or BPL ration cards to a larger section of the population (identified by the Central government as BPL) than laggard states. Table 2 shows that this is in fact the case: the proportion of BPL-plus households is significantly higher in functioning states. In 2004-2005, 49 percent of households in functioning states but only 27 percent of households in non-functioning states possessed either Antyodaya or BPL ration cards. In 2011-2012, functioning states had increased the proportion of BPL-plus households to 62 percent, and non-functioning states to 44 percent. Thus, even though the proportion of BPL-plus households increased, in both groups of states, the difference did not narrow down significantly. ${ }^{8}$

From Table 2, we can see some additional interesting trends: operational holdings and household size are both larger for non-functioning states; the proportion of illiterate population is higher in non-functioning states; the proportion of agricultural labour households and female-headed households is higher in the functioning states.

\section{III.2. Econometric Methodology}

The discussion in Section II suggests that PDS consumption is a function of prices, income and some other relevant factors (which had been abstracted from in the context of the model). While we can estimate prices of PDS and open market food grains from NSS data, the CES conducted by the NSSO does not report any data on household income. Hence, we will use wealth (as measured by the operational holding of agricultural land) and the socio-economic categories of

\footnotetext{
${ }^{8}$ The 2009-2010 CES does not have information about the possession of ration cards by households. Hence we will run regressions on two different pooled data sets. Pooled 1 will have data from 2004-2005 and 2011-2012 (with an important variable being identification of the BPL-plus households); Pooled 2 will have data from 2004-2005, 20092010 and 2011-2012 (with no information to identify BPL-plus household).
} 
caste, occupation, religion, education, and gender as proxies for income. One of the key hypotheses of this paper is the existence of socio-economic biases that operate as supply constraints in non-functioning states. We can capture the existence of such supply constraints with the interaction of each socio-economic category with a dummy variable for non-functioning states. These considerations give us the econometric model of this paper as

$$
\begin{aligned}
y_{\text {irst }}= & \alpha+\beta_{1} p_{x r}+\beta_{2} p_{y r}+\beta_{3} p_{x r}^{2}+\beta_{4} p_{y r}^{2}+\beta_{5} H S I Z E_{\text {irst }}+\gamma_{11} S E 1_{\text {irst }}+\gamma_{12} S E 1_{\text {irst }} \times \\
& N F S_{\text {irst }}+\cdots+\gamma_{k 1} S E k_{\text {irst }}+\gamma_{k 2} S E k_{\text {irst }} \times N F S_{\text {irst }}+\delta_{1} B P L_{\text {irst }}+a_{r}+b_{s}+c_{t}+ \\
& u_{\text {irst }}
\end{aligned}
$$

where $i$ indexes households, $r$ indexes state-regions, $s$ indexes states and $t$ indexes time periods, and the dependent variable is PDS consumption of food grains per month. In (1), $p_{x r}$ and $p_{y r}$ refer to the average PDS price and open market price of food grains in state-region $r$, NFS is a dummy variable that takes the value 0 if the household is located in a functioning state and 1 if the household is located in a non-functioning state, HSIZE refers to the size of the household (adults + children), SE1 through SEk refer to $k$ variables that capture socio-economic hierarchies (caste, religion, gender, education, occupation, and operational holding), BPL is a dummy variable that takes the value 1 if the household possesses either a BPL or an Antyodaya ration card (and 0 otherwise), $a_{r}$ denote state-region dummies, $b_{s}$ denote state dummies, and $c_{t}$ denote year dummies.

We would like to point out several important features of the econometric model in (1). First, as Khera (2011c) mentions, there is lot of variation across states with regard to PDS policy; we control for this variation with state dummies. Second, PDS consumption is likely to be affected by the network of fair price shops in the locality of the households. The lowest level at which we 
can define a "locality" consistently in the NSS data is the state-region. Hence, we control for differences in the network of fair price shops with state-region dummies. Third, PDS consumption might also be affected by changes in central government policies over time; we control for this effect with period dummies. Fourth, it seems safe to assume that the regressors in the model - prices and household characteristics (like caste, religion, education, wealth, gender of household head) - are all exogenous; hence, problems of endogeneity are unlikely to be serious. Hence, we estimate the model with ordinary least squares and report standard errors clustered at the state-region level to account for possible local level correlations across households.

We would like to draw attention to one important point about interpretation of coefficients on the socio-economic variables in the econometric model in (1). The coefficient on any socioeconomic variable provides an estimate of the difference in PDS consumption between the socioeconomic category and the excluded category in functioning states (NFS=0). The coefficient on the interaction of the socio-economic variable and the non-functioning state dummy provides an estimate of the change in the difference in PDS consumption between the socio-economic category and the excluded category as we move from the functioning to the non-functioning states. Hence, the sum of the coefficient on any socio-economic variable and the coefficient on the interaction of that socio-economic variable and the non-functioning state dummy provides an estimate of the difference in PDS consumption between the socio-economic category and the excluded category in the non-functioning states (NFS=1). 
To proceed to a discussion of the main results it might be useful to recall that we are interested in testing two key hypotheses: (a) that PDS consumption is supply-determined, which can be tested by seeing if the price of open market grains has a non-linear (hump-shaped) effect on consumption; and (b) PDS consumption of the privileged and the underprivileged is significantly different in functioning states but not so in non-functioning states.

[Table 3 about here]

But before we present the results, we would like to present some indirect evidence for one of our assumptions: key socio-economic categories can function as good proxies for income. To establish this connection, we present average nominal monthly consumption expenditure (as a marker of income) for different socio-economic categories in 2004-2005, 2009-2010 and 20112012 in Table 3. Data in Table 3 show clearly that agricultural labour households are also the poorest in terms of consumption expenditure; their average MPCE was Rs. 446, Rs. 768 and Rs. 1080 respectively in 2004-2005, 2009-2010 and 2011-2012. This was the lowest MPCE among all the occupational groups. Moreover, the MPCE hierarchy remained unchanged over these years with the "other" category at the top, followed by "self-employed in non-agriculture", "selfemployed in agriculture”, “other labour”, and "agricultural labour”. Turning to caste groups, we see a stable hierarchy as well: ST households are the poorest, followed by SC, OBC and other households. We see the same pattern for the education categories: illiterate households are the poorest, "above primary" households are the richest and "primary and below" are in the middle. In terms of religion also, there is a pretty stable relationship: Christians are the richest, followed by "other religions", and Hindus, with Muslims being the poorest. For gender, we see an 
unexpected but stable pattern: female-headed households are richer than male-headed households. The evidence in Table 3 is only suggestive and is meant to convey the fact that there is a relatively stable relationship between socio-economic hierarchies and income. This allows us to use these socio-economic categories as reliable proxies for income.

\section{Results and Discussion}

Table 4 presents results of estimating the model in (1) with OLS for two samples. The first sample is referred to as Pooled 1 and pools all relevant households in 2004-2005 and 2011-2012; the second sample is referred to Pooled 2 and pools together all relevant households in 20042005, 2009-2010 and 2011-2012. The advantage of using Pooled 1 is that it contains information on possession of ration cards (BPL or Antyodaya), but the disadvantage is that we lose observations for one round (2009-2010). Since possession of ration cards is an important determinant of PDS consumption, our preferred specification in Table 4 is (1). But, to use the information in 2009-2010, we re-estimate the model for Pooled 2 without the BPL-plus variable and report the results under specification (3) in Table 4. To compare the results between the two samples, we also estimate the model without the BPL-plus variable for Pooled 1 and report the results under specification (2) in Table 4.

[Table 4 about here]

\section{IV.1. Diversion of PDS Food Grains}

Our first hypothesis is that PDS consumption is not completely demand determined; it is also determined by the operation of the following supply behaviour: diversion of PDS food grains to the open market by FPS owners. To test this we analyse the coefficient on open market price and 
its square. ${ }^{9}$ All three specifications in Table 4 show that the coefficient on open market price is positive and on its square is negative, with both being statistically significant. For specification (1), our preferred specification, an increase in the open market price of food grains by $1 \mathrm{Re} / \mathrm{kg}$ leads to an increase in PDS consumption by $3.054 \mathrm{~kg} / \mathrm{month} / \mathrm{household}$. This is to be expected: as open market price increases, consumers substitute away from open market and towards PDS food grain. But the coefficient on the square of the open market price is -0.073 , which implies that open market price has a non-linear (hump-shaped) effect on PDS consumption. In fact, the result for specification (1) in Table 4 suggests that when open market price is higher than 20.92 Rs $/ \mathrm{kg}(=3.054 / 2 * 0.073)$, the marginal effect of open market price on PDS consumption is negative: an increase of open market price by $1 \mathrm{Re} / \mathrm{kg}$, leads to PDS consumption falling by 73 grams. This hump-shaped behaviour suggests that PDS consumption is not completely demanddetermined.

One way to understand this hump-shaped behaviour is to think of the effect of an increase in the open market price of food grains on both the demand and supply of PDS food grains. When the open market price of food grains increase, it leads to an increase in the demand for PDS food grains. At the same time, an increase in the open market price of food grains increases the incentive of fair price owners to divert PDS food grains to the open market. At high values of the open market price, diversion becomes large and PDS consumption starts declining (hence the negative marginal effect of open market price on PDS consumption).

\footnotetext{
${ }^{9}$ It is possible that expectations of future open market prices have an impact on PDS consumption through the following mechanism: FPS owners are more likely to hoard PDS food grains if they expect the open market price to increase in the future; this might reduce the supply, and hence the consumption of PDS food grains. While this is a plausible mechanism, we do not have data on expected prices. Hence, we cannot include expected price as a control. While this might give a biased coefficient on price variables (if current and expected prices are correlated), it will not affect our main results to any significant extent. This is because all non-price regressors - most of which are household level characteristics - in the empirical model can be expected to be independent of prices.
} 
This has an important implication. In the presence of binding supply constraints, the issue of access to the PDS becomes very important in determining consumption of PDS food grains by individual households. It is no longer a matter of demand alone. Some households are not able to purchase the amount they demand. In such a scenario, gradients of social power can be used to limit access of the underprivileged to PDS entitlements. On the one hand this would reduce PDS consumption; on the other, it would increase diversion.

Before we turn to investigating this issue through our second hypothesis regarding the difference in PDS consumption between privileged and under-privileged households, let us analyse four important effects: wealth, household size, ration card (BPL or Antyodaya) and non-functioning states. Since the CES does not have data on total wealth, we use the size of the operational land holding as a proxy for wealth. Recall that we have restricted our analysis to rural areas, which is still dominated by agriculture. Hence, size of the operational holding is likely to be a good proxy for wealth. ${ }^{10}$ In specifications (1) (2), and (3) in Table 4, the coefficient on operational holding of land is negative but statistically insignificant; the coefficient on the interaction of land with the dummy for non-functioning states is positive, but again insignificant. This implies that the effect of landholding is not very strong on PDS consumption in either groups of states.

In all the three specification in Table 4, household size has a positive and statistically significant effect on PDS consumption. The estimates suggest that a household with one more member will roughly consume $0.8 \mathrm{~kg}$ more food grains from the PDS. This positive effect is the result of two factors. One the supply side, larger household size might increase the PDS entitlement of the households; on the demand side, more household members mean more food requirement and

\footnotetext{
${ }^{10}$ Note that we have not included total expenditure as a regressor in model (1). This is because total expenditure is jointly determined with PDS purchase by households. Hence, we control for prosperity levels of households with wealth (as measured by the size of the operational holding of agricultural land).
} 
also that the chance of someone from the family going to the fair price shop at the relevant time to purchase PDS food grains increases.

In specification (1) in Table 4, the coefficient on the ration card (BPL or Antyodaya) dummy is 10.069; hence, households that possess Antyodaya or BPL ration cards consume 10.069 kgs more food grains than those that do not. The interaction term (ration card $\mathrm{X}$ non-functioning states) is positive (3.125) and statistically insignificant. Hence, in non-functioning states households with ration cards consume about 13 kgs more PDS grains per month than households without ration cards. When we recall that functioning states have significantly higher proportion of households with ration cards than non-functioning states (see Table 2 for details), this throws light on an interesting dimension: functioning states do better at increasing access to the PDS by distributing ration cards, but do worse off in converting each ration card into PDS purchase. Hence, one way in which non-functioning states can improve is to be more pro-active in identifying BPL households and distributing ration cards.

In all the three specifications in Table 4, the coefficient on the non-functioning state dummy is large and negative (-10.13 in the first specification) and strongly statistically significant; on the other hand, the coefficient on the interaction of the non-functioning state dummy with year dummies is not significant. The negative effect of the non-functioning state dummy suggests that even after controlling for prices, household level characteristics, and state region fixed effects, PDS consumption is significantly lower for all households in non-functioning states (NFS=1) in comparison to functioning states (NFS $=0$ ). ${ }^{11}$ This result indicates that there is a relatively large and constant premium (in terms of PDS consumption) that attaches to households in functioning

\footnotetext{
${ }^{11}$ The fact that the coefficient on the interaction of the NFS dummy with the year dummies are not statistically significant suggest that the effect does not change over time.
} 
states even after accounting for prices, socio-economic biases and possession of ration cards. While in this paper we have investigated the effect of socio-economic biases on PDS consumption, and therefore focused on the difference in PDS consumption between privileged and under-privileged households, other factors that operate on all households are also important. These could be investigated in the future.

\section{IV.2. Socio-Economic Hierarchies and PDS Consumption}

The key insight of the economic model developed in Section II is that PDS consumption of the privileged and under-privileged differ significantly in functioning states (NFS=0) but might be close to each other in non-functioning states (NFS=1). We can test this insight using the results reported in Table 4 for different dimensions of social hierarchy.

Let us begin with the dimension of caste. Our data set allows us to classify households into four caste/ethnicity groups: scheduled castes (SC), scheduled tribes (ST), other backward castes (OBC) and others, with the last category referring to the privileged sections. In the regression, we leave out the dummy for “others” (upper caste group) and make it the reference caste group. In specification (1) in Table 4, the coefficients on the ST and OBC dummies are positive but statistically insignificant. Thus, in functioning states, PDS consumption of ST and OBC households are not different from "other” households (the excluded caste category). But the coefficient on the SC dummy (0.992) is positive and significant. Hence, in functioning states, SC households consume more PDS food grains than upper caste (the excluded category) households.

[Table 5 about here] 
How do SC, ST and OBC households fare with respect to upper caste households in nonfunctioning states? To answer this question, we can turn to Table 5, where we report estimates of the difference in PDS consumption between underprivileged and privileged categories households across key socio-economic hierarchies. The first two rows refer to caste hierarchies, providing estimates of the difference in PDS consumption in non-functioning states between SC and upper caste households, and between ST and upper caste households, respectively. We also report the F-stat and p-value for the test that this difference is zero.

The result in Table 5 shows that the difference in PDS consumption between SC/OBC and upper caste households is negative but not statistically significantly different from zero at standard levels of significance; but the difference in PDS consumption between ST and upper caste households is negative and statistically significant. Thus, the results in Table 4 and 5 together show that functioning states manage to generate higher PDS consumption for one category of under-privileged households: SC households have higher PDS consumption relative to upper caste households. In non-functioning states, the story is more complex. While PDS consumption between SC/OBC and upper caste households is not significantly different, ST households have lower consumption than upper caste households.

Turning to the dimension of religion, we see that the results for all specifications in Table 4 are statistically insignificant. The reference religion category is Hindu (the privileged group). ${ }^{12}$ Hence, we can conclude that neither do functioning states perform better along the hierarchy of religion, nor are non-functioning states relatively worse than functioning states in providing

\footnotetext{
${ }^{12}$ We treat Hindus as the privileged religious group, keeping in mind the fact that they are privileged with respect to Muslims, the latter being the other large religious group in India. In terms of MPCE, Hindus are not the richest religious group. Christians and "other religious groups" have higher MPCE than Hindus, and Muslims have lower MPCE than Hindus. But both Christians and "other religious groups" are numerically small in India.
} 
access to religious minorities. For instance, the difference in PDS consumption between Muslims and Hindus (the excluded religion category) is not significantly different in functioning states (the coefficient on the Muslim dummy is 0.171 but insignificant); neither is the difference in this dimension between functioning and non-functioning states important (the coefficient on the interaction term with the Muslim dummy is -0.59 but insignificant).

When we turn to the dimension of formal education, we use illiterates (the least privileged) as the reference group. For specification (1) in Table 4, the coefficient on "primary and below" is insignificant. Thus, the difference in PDS consumption between "primary and below" households and illiterate households (the excluded category of educational category) is not significant in functioning states. But the coefficient on the "above primary" category is negative $(-0.943)$ and significant, suggesting that in functioning states, households with above primary schooling consume $0.943 \mathrm{~kg}$ less PDS food grains than illiterate households. To see how this difference looks in non-functioning states, we can turn to Table 5. In non-functioning states the difference in PDS consumption between illiterate and "above primary" households is not statistically different from zero (the difference is 0.306 and the p-value is 0.41 ). In sum, Tables 4 and 5 show that functioning states are able to ensure higher PDS consumption for the underprivileged (illiterate households) relative to privileged households (those with aboveprimary schooling); but we do not observe a significant difference in PDS consumption between under-privileged and privileged households in non-functioning states.

The next dimension of socio-economic hierarchy in our analysis is occupation. We have data on five categories of occupation - self-employed in non-agriculture, agriculture labour, other labour, self-employed in agriculture and other - and use agriculture labour (the least privileged) as the reference category. In specification (1) in Table 4, we see that the coefficient on "self-employed 
in non-agri” dummy to be -1.444 and strongly significant. This means that in functioning states, households that are self-employed in the non-agricultural sector consumer $1.444 \mathrm{~kg}$ less PDS food grains than agricultural labour households (the excluded occupation category). We see similar results for "self-employed in agriculture” and "other” (professionals): both these groups consume significantly less PDS food grains than agricultural labour households in functioning states.

To see how these differences in PDS consumption operate in non-functioning states, we use the results in Table 5. The striking result in Table 5 is that the difference in PDS consumption between agricultural labour households and each of the other occupation categories are not significantly different from zero in non-functioning states. For the categories of "self-employed in non-agriculture”, “self-employed in agriculture”, and "other” (professionals), the null hypothesis of the equality in average PDS consumption between agricultural labour households and these groups of households cannot be rejected at standard levels of statistical significance. If occupation is roughly congruent with class position, then Tables 4 and 5 show a striking result. Functioning states manage to ensure more PDS food grains to those occupying the lowest position in the class hierarchy (agricultural labour households) relative to those above (selfemployed in agriculture, self-employed in agriculture, and professional households); in nonfunctioning states we do not observe this difference.

The last dimension of socio-economic hierarchy that we analyse is gender. We capture the effect of gender by a dummy variable that takes the value 1 for female-headed households and 0 otherwise. In all specifications in Table 4, we see that the sign on the female-headed household dummy is negative and significant. This means that in functioning states, female-headed households consume less PDS food grains than male-headed households. For instance, according 
to specification (1) in Table 4, female-headed households consume $1.497 \mathrm{~kg}$ less PDS food grains than male-headed households in functioning states. The apparent anomaly in this result vanishes once we recall that female-headed households are richer than male-headed households (as we see in Table 3). The economic model in section II predicts that poorer households will consume more PDS food grains in functioning states, and that is what we find with regard to female-headed households. On the other hand, the result in Table 5 shows that the female-headed consume $1.227 \mathrm{~kg}$ per month more PDS food grains than male-headed households in nonfunctioning states. This result is surprising and unexpected. Given that female-headed households are richer in terms of MPCE - as seen from Table 3 - one would have expected to see at most equal PDS consumption between these and male-headed households. The fact that female-headed households consume $1.227 \mathrm{~kg}$ per month more PDS food grains than maleheaded households, according to results in Table 5, might be because the category of "femaleheaded” household is not good for capturing gender biases. It may be more appropriate to explore alternative categories for better capturing gender bias in future research.

To summarise the results in this sub-section we would like to highlight two points: (a) for key socio-economic dimensions of privilege, functioning states manage to provide higher PDS consumption to the underprivileged; and (2) in non-functioning states, the observed consumption of PDS food grains is not significantly different between underprivileged and privileged households.

To interpret these result, recall that socio-economic dimensions of privilege are strongly correlated with income (according to the indirect evidence in Table 3); thus, those occupying lower positions in the socio-economic hierarchy are also poorer. The model in section II suggests that the demand for PDS food grains will be higher for these underprivileged groups. The fact 
that functioning states have managed to nullify biases in the access of PDS operating through the dimensions of socio-economic privilege means that underprivileged households manage to get a relatively high share of PDS food grains they demand. This shows up as significant difference in the observed PDS consumption between the under privileged and privileged households in functioning states. But in non-functioning states, the biases are strong and prevent underprivileged households from getting even a small share of what they demand. Hence, they end up with consuming small amounts of PDS food grains, which is not significantly different from what the privileged households consume by choice.

It is worth noting that our results paint a different picture for religion. While Hindus (the excluded religion category in Table 4) are not the richest group, Muslims have the lowest MPCE (see Table 3). Thus, one would have expected to see some significantly higher consumption of PDS food grains by Muslims in functioning states. The fact that we do not see this result in Table 4 perhaps points to the fact that even while addressing many socio-economic biases, wellfunctioning states have not been able to address the bias that flows from the religion of households.

Another interesting dimension of the results presented in Table 4 emerges from a comparison of specification 1 and 2. Recall that the only difference between the two specifications is the inclusion of the dummy for the possession of ration cards (BPL or Antyodaya) in specification 1 and its exclusion in specification 2. A comparison of the coefficients on the different caste, education, and occupation categories show that the magnitude (and statistical significance) is lower in specification 1. For instance, in specification 2, the coefficient on ST is 3.199 and statistically significant; but the corresponding coefficient in specification 1 is 0.929 and statistically insignificant. We see a similar pattern for the coefficients on SC, OBC, above- 
primary, and all the occupation categories. This means that in functioning states, a significant reason for larger PDS consumption by under-privileged households comes from the possession of ration cards (BPL or Antyodaya). This is another piece of evidence in support of the claim that one of the important ways in which non-functioning states could improve their PDS delivery and reach is by pro-actively identifying and distributing ration cards to BPL households.

\section{IV.3. PDS Consumption and Diversion}

As we had indicated above there is a negative relationship between PDS consumption and diversion of PDS food grains made available by the central government to individual states. This is easy to see: if households in a state manage to consume more food grains from the PDS, less is available to be diverted to the open market. Hence, in a mechanical fashion, high consumption from PDS leads to lower diversion (once we take account of state-level offtake) and vice versa. To see that this is indeed the case, in Figure 1 we show a scatter plot of PDS consumption and diversion - recall that diversion is defined as one minus the ratio of NSS consumption and statelevel offtake - across Indian states in 2011-2012. Data for the scatter plot is from Table 1, and we include a regression line to capture the statistical relationship between the two variables. The regression line in Figure 1 has a negative slope of 2.89 that is statistically significant. This means that across Indian states in 2011-2012, an increase in PDS consumption by $1 \mathrm{~kg} /$ household is associated with 2.89 percentage point lower diversion.

[Figure 1 about here]

\section{Conclusion}

The public distribution system in India has attracted lot of academic and policy attention in recent years. Critics have highlighted the leakage and corruption that plague the system and some have called for the replacement of the existing in-kind subsidy system by an in-cash 
system. While leakage and corruption that beset the PDS is undeniable, two important facts need to be noted about this. First, leakage (or diversion) of food grains from the PDS has secularly declined over time. Second, there is large variation in leakage across Indian states, with some states like Tamil Nadu, Himachal Pradesh and Andhra Pradesh consistently performing well with regard to the PDS. Both these facts suggest that the existing in-kind PDS is not beyond redemption. In this paper, we focus on the variation of PDS performance - measured by PDS consumption of food grain per household - in rural areas across states to ask the following question: what makes some states more successful than others in delivering PDS food grains to rural households?

We construct a simple one-period two-commodity consumer choice model to think about this issue. In our model, households choose between PDS food grains and open market food grains to meet a minimum requirement under a given budget constraint. We show that consumption of PDS food grains will differ significantly between rich (or privileged) and poor (underprivileged) households in states where supply constraints on the poor are not stringent. On the other hand, in states where supply constraints are stringent and binding, consumption of PDS food grains will not differ significantly between rich and poor households.

Using household-level consumption data from the three most recent "thick" rounds of the consumption expenditure survey of the NSSO, we test our hypothesis in two steps by estimating a regression model with a pooled data set. In the first step, we establish that PDS consumption is not completely demand determined; it is impacted by supply constraints arising from the diversion of PDS food grains to the open market by FPS owners. In the second step we show that in states where the PDS is relatively well functioning, households lower down in the caste hierarchy, in the occupational hierarchy, and in the educational hierarchy consume more PDS 
food grains than those higher up in the hierarchy. We find no such egalitarian effect in states where the PDS has not been functioning well. This provides evidence in support of our hypothesis: taming socio-economic biases will help in improving the reach and delivery of the PDS. One important set of factors that makes states better at delivering PDS food grains to its citizens is probably a combination of pro-active public policy and grassroots mobilisation that counters the influence of socio-economic hierarchies in generating supply constraints for underprivileged households. ${ }^{13}$ Our results suggest that pro-active state policy in identifying and distributing ration cards to BPL (and Antyodaya) households could be one straightforward way to improve the reach, delivery and performance of the PDS.

We would like to end by pointing out that the analysis in this paper addresses concerns raised in Kotwal et al. (2011) and Khera (2011a). Commenting on the argument that the existing in-kind PDS can be reformed, Kotwal et al. (2011) point out that such a case cannot be made on the basis of two relatively successful states only, Tamil Nadu and Chhattisgarh. In this paper, we have moved beyond individual states and compared the performance of seven well-functioning with eight non-functioning states. Hence, the analysis in this paper addresses the concern raised in Kotwal et al. (2011) that "[two] relative successes do not convincingly swing the case in favour of PDS, when the system has failed consistently in most states."'

Coming at the issue from an opposite end, Khera (2011a) argues that aggregate all-India level analysis is not meaningful because of differences in the PDS across states. While it is certainly true that there are many differences among states with regard to the PDS, this does not detract from aggregate analysis. In fact, by classifying states into three broad categories - functioning,

\footnotetext{
${ }^{13}$ Some of the concrete measures that have probably contributed to mitigating the effects of socio-economic biases are (a) the replacement of privately run fair price shops with those run by cooperatives (Tamil Nadu and Chhattisgarh), (b) the establishment of fair price shops operated by women (Tamil Nadu and Chhattisgarh).
} 
reforming and languishing - Khera (2011b) highlights the commonality among the many states that fall into each of these categories. In this paper, we extend the analysis in Khera (2011b) and investigate the reasons that make the PDS function well in some states. In our analysis, we recognise the importance of state-level variation and take account of their effects in our empirical model with state-level dummies.

One possible drawback of the analysis in this paper is that it uses a pooled data set for estimating the empirical model. Hence, we are unable to control for household-level unobserved heterogeneity. In future research, it might be useful to explore the option of either constructing pseudo-panel data sets at the district or state-region level, or using fieldwork to construct a panel data set at the household level. Both these approaches would address the problem of unobserved heterogeneity. 


\section{References}

Balakrishnan, P., \& Ramaswami, B. (1997). Quality of Public Distribution System: Why it Matters. Economic and Political Weekly, 32(4), 162-165.

GOI, (2013). The National Food Security Bill, 2013. Government of India. (Retrieved from http://indiacode.nic.in/acts-in-pdf/202013.pdf)

Basu, D., \& Basole, A. (2014). Fueling Calorie Intake Decline: Household Level Evidence from Rural India. Working Paper 348, Political Economy Research Institute, University of Massachusetts Amherst. (Retrieved from http://www.peri.umass.edu/fileadmin/pdf/working_papers/working_papers_301-350/WP348.pdf)

Himanshu, \& Sen, A. (2011). Why Not a Universal Food Security Legislation?. Economic and Political Weekly, 46(12), 38-47.

---. (2013a). In-Kind Food Transfers - I: Impact on Poverty. Economic and Political Weekly,48(45 \& 46), 46-54.

---. (2013b). In-Kind Food Transfers - II: Impact on Nutrition and Implications for Food Security and Its Costs. Economic and Political Weekly, 48(47), 60-73.

Khera, R. (2011a). India's Public Distribution System: Utilisation and Impact. Journal of Development Studies, 47(7), 1038-1060.

---. (2011b). Trends in Diversion of Grain from the Public Distribution System. Economic and Political Weekly, 46(21), 106-14.

---. (2011c). Revival of the Public Distribution System: Evidence and Explanations. Economic and Political Weekly, 46(44 \& 45), 36-50.

Kotwal, A., Murugkar, M., \& Ramaswami, B. (2011). PDS Forever?. Economic and Political Weekly, 46(21), 72-76. 
Swaminathan, M. (2000). Consumer Goods Subsidies in India: Proposals for Reform. Journal of Peasant Studies, 27(3), 92-114.

---. (2001). Errors of Targeting: Public Distribution of Food in a Maharashtra Village, 19952000. Economic and Political Weekly, 36(26), 2447-2454.

---. (2008). Programmes to Protect the Hungry: Lessons from India. DESA Working Paper No. 70. (ST/ESA/2008/DWP/70). United Nations Department of Economic and Social Affairs. (Retrieved from http://www.un.org/esa/desa/papers/2008/wp70_2008.pdf) 
Table 1: Consumption and Diversion from PDS (kg per household per month)

\begin{tabular}{|c|c|c|c|c|c|c|c|c|c|c|}
\hline & \multicolumn{3}{|c|}{ 2004-2005 } & \multicolumn{3}{|c|}{ 2009-2010 } & \multicolumn{4}{|c|}{ 2011-2012 } \\
\hline & Grains & Rice & Wheat & Grains & Rice & Wheat & Grains & Rice & Wheat & Diversion \\
\hline Andaman \& Nicobar Is & 17.75 & 17.58 & 0.18 & 17.97 & 16.33 & 1.65 & 20.57 & 17.84 & 2.73 & -26.28 \\
\hline Andhra Pradesh & 9.39 & 9.37 & 0.02 & 12.02 & 11.96 & 0.07 & 11.23 & 11.11 & 0.12 & 12.22 \\
\hline Arunachal Pradesh & 17.20 & 16.95 & 0.25 & 17.25 & 16.99 & 0.26 & 17.75 & 17.47 & 0.28 & -556.31 \\
\hline Assam & 2.29 & 2.28 & 0.00 & 6.98 & 6.92 & 0.06 & 13.42 & 13.25 & 0.17 & 43.80 \\
\hline Bihar & 0.52 & 0.20 & 0.32 & 3.62 & 1.98 & 1.64 & 11.76 & 6.73 & 5.03 & -1.91 \\
\hline Chandigarh & 0.10 & 0.10 & 0.00 & 2.18 & 0.79 & 1.39 & 3.38 & 0.59 & 2.79 & 78.70 \\
\hline Chhattisgarh & 7.42 & 7.00 & 0.42 & 21.94 & 20.33 & 1.61 & 19.27 & 17.31 & 1.96 & -10.16 \\
\hline Dadra \& Nagar Haveli & 10.36 & 8.72 & 1.63 & 6.09 & 5.53 & 0.57 & 9.39 & 8.94 & 0.45 & 42.23 \\
\hline Daman \& Diu & 1.51 & 0.91 & 0.60 & 6.09 & 5.02 & 1.07 & 1.08 & 0.94 & 0.14 & 99.72 \\
\hline Delhi & 1.13 & 0.28 & 0.85 & 1.45 & 0.09 & 1.36 & 2.62 & 0.41 & 2.21 & 83.54 \\
\hline Goa & 2.87 & 2.52 & 0.34 & 7.56 & 7.13 & 0.42 & 9.43 & 8.20 & 1.23 & 33.86 \\
\hline Gujarat & 3.04 & 0.93 & 2.10 & 3.99 & 1.31 & 2.67 & 2.90 & 0.90 & 1.99 & 68.71 \\
\hline Haryana & 1.41 & 0.00 & 1.41 & 5.27 & 0.00 & 5.27 & 4.93 & 0.12 & 4.81 & 53.92 \\
\hline Himachal Pradesh & 14.21 & 8.82 & 5.39 & 20.31 & 7.85 & 12.45 & 23.48 & 9.22 & 14.26 & 19.91 \\
\hline Jammu \& Kashmir & 20.31 & 18.37 & 1.95 & 30.03 & 23.97 & 6.06 & 30.54 & 22.67 & 7.87 & -1.36 \\
\hline Jharkhand & 1.30 & 0.73 & 0.57 & 6.69 & 4.40 & 2.29 & 8.78 & 8.60 & 0.18 & 34.57 \\
\hline Karnataka & 10.97 & 9.34 & 1.64 & 10.55 & 9.02 & 1.53 & 10.94 & 9.33 & 1.61 & 24.89 \\
\hline Kerala & 7.72 & 6.99 & 0.73 & 9.41 & 8.03 & 1.37 & 12.02 & 10.40 & 1.61 & 22.59 \\
\hline Lakshadweep & 45.52 & 45.45 & 0.07 & 36.97 & 36.35 & 0.62 & 38.82 & 38.52 & 0.30 & -18.15 \\
\hline Madhya Pradesh & 6.08 & 1.63 & 4.44 & 9.09 & 1.60 & 7.49 & 9.10 & 2.00 & 7.10 & 37.51 \\
\hline Maharashtra & 5.53 & 2.24 & 3.30 & 8.44 & 3.79 & 4.65 & 8.82 & 4.03 & 4.79 & 29.99 \\
\hline Manipur & 0.20 & 0.20 & 0.00 & 1.88 & 1.87 & 0.01 & 1.12 & 1.10 & 0.02 & 95.63 \\
\hline Meghalaya & 5.70 & 5.70 & 0.00 & 14.25 & 14.25 & 0.01 & 13.85 & 13.80 & 0.05 & 53.13 \\
\hline Mizoram & 24.14 & 24.08 & 0.06 & 25.48 & 25.23 & 0.25 & 29.00 & 28.67 & 0.33 & -3.20 \\
\hline Nagaland & 0.01 & 0.00 & 0.00 & 0.00 & 0.00 & 0.00 & 3.85 & 3.85 & 0.01 & 90.65 \\
\hline Odisha & 4.03 & 4.01 & 0.02 & 14.01 & 13.48 & 0.53 & 15.22 & 14.37 & 0.85 & 15.19 \\
\hline Puducherry & 8.54 & 8.41 & 0.14 & 12.15 & 10.67 & 1.48 & 13.04 & 10.23 & 2.81 & -1.36 \\
\hline Punjab & 0.15 & 0.01 & 0.14 & 4.46 & 0.00 & 4.46 & 4.48 & 0.02 & 4.46 & 60.73 \\
\hline Rajasthan & 3.99 & 0.00 & 3.99 & 4.42 & 0.00 & 4.42 & 6.28 & 0.07 & 6.21 & 47.92 \\
\hline Sikkim & 15.05 & 15.02 & 0.02 & 14.60 & 14.53 & 0.07 & 15.84 & 15.82 & 0.02 & 42.25 \\
\hline Tamil Nadu & 13.82 & 13.46 & 0.36 & 16.85 & 15.44 & 1.41 & 16.36 & 14.75 & 1.61 & 6.28 \\
\hline Tripura & 10.93 & 10.85 & 0.08 & 18.25 & 17.73 & 0.52 & 21.82 & 21.51 & 0.31 & 24.11 \\
\hline Uttar Pradesh & 1.69 & 0.70 & 0.99 & 6.63 & 3.56 & 3.07 & 7.51 & 4.07 & 3.44 & 51.62 \\
\hline Uttarakhand & 7.79 & 4.36 & 3.43 & 7.68 & 4.28 & 3.40 & 15.24 & 7.87 & 7.37 & 96.32 \\
\hline West Bengal & 1.71 & 1.11 & 0.60 & 3.91 & 2.17 & 1.74 & 5.83 & 3.41 & 2.41 & 58.37 \\
\hline INDIA & 5.21 & 3.87 & 1.33 & 8.71 & 6.10 & 2.61 & 10.01 & 6.91 & 3.10 & 29.43 \\
\hline
\end{tabular}

Note: grains $=$ rice + wheat; diversion $=100 *(1-$ NSS consumption/Offtake); data is from rounds 61,66 and 68 of the CES; authors' calculations using NSS supplied sampling weights. 


\begin{tabular}{|c|c|c|c|c|c|c|c|c|c|c|c|c|}
\hline & \multicolumn{4}{|c|}{ 2004-05 } & \multicolumn{4}{|c|}{ 2009-10 } & \multicolumn{4}{|c|}{ 2011-12 } \\
\hline & \multicolumn{2}{|c|}{$\mathrm{NFS}=1$} & \multicolumn{2}{|c|}{$\mathrm{NFS}=0$} & \multicolumn{2}{|c|}{ NFS=1 } & \multicolumn{2}{|c|}{ NFS $=0$} & \multicolumn{2}{|c|}{$\mathrm{NFS}=1$} & \multicolumn{2}{|c|}{ NFS $=0$} \\
\hline & Mean & SD & Mean & SD & Mean & SD & Mean & SD & Mean & SD & Mean & SD \\
\hline PDS consumption of grains ( $\mathrm{kg} / \mathrm{hhld} / \mathrm{month})$ & 2.11 & 7.94 & 11.17 & 12.62 & 5.06 & 10.47 & 14.23 & 12.14 & 8.80 & 12.70 & 14.50 & 11.93 \\
\hline Market price of grains (Rs/kg) & 9.65 & 1.17 & 11.78 & 1.32 & 15.87 & 1.61 & 21.08 & 2.73 & 17.36 & 2.42 & 21.83 & 3.08 \\
\hline PDS price of grains (Rs/kg) & 5.31 & 1.45 & 5.39 & 1.27 & 5.59 & 1.26 & 4.15 & 2.35 & 5.25 & 1.48 & 5.17 & 2.82 \\
\hline Land operated (acres) & 1.73 & 2.66 & 1.59 & 2.63 & 1.57 & 2.66 & 1.39 & 2.39 & 1.45 & 2.54 & 1.38 & 2.36 \\
\hline Household Size (number) & 5.10 & 2.33 & 4.35 & 2.00 & 4.94 & 2.17 & 4.20 & 1.91 & 4.85 & 2.07 & 4.06 & 1.91 \\
\hline \multicolumn{13}{|l|}{ Proportion of Households: } \\
\hline Scheduled Tribe & 0.11 & 0.31 & 0.07 & 0.26 & 0.12 & 0.32 & 0.06 & 0.24 & 0.11 & 0.31 & 0.07 & 0.26 \\
\hline Scheduled Caste & 0.23 & 0.42 & 0.19 & 0.39 & 0.24 & 0.43 & 0.19 & 0.39 & 0.22 & 0.41 & 0.19 & 0.39 \\
\hline Other Backward Classes & 0.35 & 0.48 & 0.47 & 0.50 & 0.34 & 0.48 & 0.52 & 0.50 & 0.37 & 0.48 & 0.52 & 0.50 \\
\hline Other Castes & 0.32 & 0.47 & 0.26 & 0.44 & 0.30 & 0.46 & 0.23 & 0.42 & 0.30 & 0.46 & 0.22 & 0.41 \\
\hline Hindus & 0.78 & 0.41 & 0.87 & 0.34 & 0.78 & 0.41 & 0.86 & 0.35 & 0.78 & 0.41 & 0.87 & 0.34 \\
\hline Muslims & 0.16 & 0.36 & 0.07 & 0.26 & 0.16 & 0.37 & 0.08 & 0.27 & 0.16 & 0.37 & 0.08 & 0.27 \\
\hline Christian & 0.01 & 0.10 & 0.04 & 0.20 & 0.01 & 0.10 & 0.05 & 0.21 & 0.01 & 0.10 & 0.04 & 0.19 \\
\hline Other Religions & 0.05 & 0.23 & 0.02 & 0.13 & 0.05 & 0.22 & 0.02 & 0.13 & 0.05 & 0.21 & 0.01 & 0.12 \\
\hline Illiterate & 0.45 & 0.50 & 0.44 & 0.50 & 0.41 & 0.49 & 0.37 & 0.48 & 0.40 & 0.49 & 0.37 & 0.48 \\
\hline Primary and below & 0.27 & 0.44 & 0.26 & 0.44 & 0.28 & 0.45 & 0.29 & 0.45 & 0.28 & 0.45 & 0.27 & 0.44 \\
\hline Above Primary & 0.28 & 0.45 & 0.30 & 0.46 & 0.30 & 0.46 & 0.34 & 0.47 & 0.32 & 0.47 & 0.36 & 0.48 \\
\hline Self Employed in Non Agriculture, proportion & 0.18 & 0.38 & 0.14 & 0.35 & 0.19 & 0.39 & 0.13 & 0.34 & 0.19 & 0.39 & 0.15 & 0.35 \\
\hline Agricultural Labour & 0.24 & 0.43 & 0.36 & 0.48 & 0.25 & 0.44 & 0.34 & 0.48 & 0.20 & 0.40 & 0.28 & 0.45 \\
\hline Other Labour & 0.10 & 0.31 & 0.12 & 0.33 & 0.14 & 0.35 & 0.16 & 0.37 & 0.13 & 0.34 & 0.11 & 0.32 \\
\hline Self Employed in Agriculture & 0.37 & 0.48 & 0.27 & 0.45 & 0.32 & 0.47 & 0.25 & 0.43 & 0.35 & 0.48 & 0.28 & 0.45 \\
\hline Other & 0.10 & 0.31 & 0.11 & 0.31 & 0.10 & 0.30 & 0.11 & 0.32 & 0.13 & 0.34 & 0.18 & 0.38 \\
\hline Female Headed Household & 0.10 & 0.29 & 0.14 & 0.35 & 0.09 & 0.28 & 0.14 & 0.35 & 0.09 & 0.29 & 0.17 & 0.37 \\
\hline Possess Ration Card (BPL or Antyodaya) & 0.27 & 0.44 & 0.49 & 0.50 & & & & & 0.44 & 0.50 & 0.62 & 0.48 \\
\hline
\end{tabular}

Note: NFS=1: non-functioning states; NFS=0: functioning states; data is for rural areas from rounds 61,66 and 68 of the CES; authors' calculations. 
Table 3: Average Monthly Per Capita Expenditure by Different Socio-Economic Categories in Rural India (Rs.)

2004-2005 2009-2010 2011-2012

\section{Occupation Categories}

Self Employed in Non Agri

$\begin{array}{lcc}655.7 & 1049.0 & 1481.3 \\ 445.7 & 768.4 & 1079.8 \\ 561.1 & 925.6 & 1166.9 \\ 615.8 & 1037.9 & 1382.6 \\ 886.4 & 1432.3 & 1898.2\end{array}$

\section{Caste Categories}

ST

$\mathrm{SC}$

451.8

789.4

1034.0

506.3

846.4

1201.1

OBC

597.5

992.1

1393.9

Others

734.6

1208.0

1672.7

\section{Religion Categories}

Hindu

584.4

$968.2 \quad 1350.6$

Muslim

591.1

$920.8 \quad 1288.6$

Christian

890.9

1642.7

2121.5

Others

782.9

1379.2

2011.2

\section{Education Categories}

Illiterate

495.0

840.0

1145.6

Primary and Below

583.2

952.5

1290.0

Above Primary

774.0

1213.4

1715.6

\section{Gender Categories}

Male Headed Household

591.6

974.4

1361.5

Female Headed Household

$646.9 \quad 1120.9$

1487.5

Note: data is for rural areas from rounds 61, 66 and 68; authors' calculations. 


\begin{tabular}{|c|c|c|c|}
\hline \multirow[b]{2}{*}{ Dep Var: Grain (rice + wheat) consumption from PDS } & \multicolumn{2}{|c|}{ Pooled 1} & \multirow{2}{*}{$\frac{\text { Pooled } 2}{(3)}$} \\
\hline & (1) & $(2)$ & \\
\hline \multirow[t]{2}{*}{ Open market price } & $3.054^{*}$ & 2.383 & $1.966^{*}$ \\
\hline & $(1.633)$ & $(1.589)$ & $(1.070)$ \\
\hline \multirow[t]{2}{*}{ PDS Price } & 0.411 & 0.373 & 0.095 \\
\hline & $(0.293)$ & $(0.245)$ & (0.174) \\
\hline \multirow[t]{2}{*}{ Open market price squared } & $-0.073 * *$ & $-0.057^{*}$ & $-0.047 *$ \\
\hline & $(0.033)$ & $(0.032)$ & $(0.023)$ \\
\hline \multirow[t]{2}{*}{ Ration Card (BPL or Antyodaya) } & $10.069 * * *$ & & \\
\hline & $(1.411)$ & & \\
\hline \multirow[t]{2}{*}{ Ration Card (BPL or Antyodaya) X NFS } & $3.125^{*}$ & & \\
\hline & $(1.734)$ & & \\
\hline \multirow[t]{2}{*}{ NFS } & $-10.130 * * *$ & $-9.115^{* *}$ & $-10.103 * * *$ \\
\hline & (3.429) & $(3.532)$ & $(1.854)$ \\
\hline \multirow[t]{2}{*}{ ST } & 0.929 & $3.199 * * *$ & $3.063 * * *$ \\
\hline & $(0.957)$ & $(0.785)$ & $(0.810)$ \\
\hline \multirow[t]{2}{*}{ ST X NFS } & $-2.266 * * *$ & -1.623 & -1.206 \\
\hline & $(0.739)$ & $(0.968)$ & $(1.076)$ \\
\hline \multirow[t]{2}{*}{ SC } & $0.992 *$ & $2.222^{* * *}$ & $2.130 * * *$ \\
\hline & $(0.492)$ & $(0.501)$ & $(0.501)$ \\
\hline \multirow[t]{2}{*}{ SCXNFS } & $-1.177^{* *}$ & -0.454 & -0.216 \\
\hline & $(0.495)$ & $(0.690)$ & $(0.635)$ \\
\hline \multirow[t]{2}{*}{$\mathrm{OBC}$} & 0.206 & $0.857^{*}$ & $1.022 * *$ \\
\hline & $(0.460)$ & $(0.469)$ & $(0.433)$ \\
\hline \multirow[t]{2}{*}{ OBC X NFS } & -0.539 & $-0.879 *$ & $-0.970 * *$ \\
\hline & $(0.327)$ & $(0.451)$ & $(0.445)$ \\
\hline \multirow[t]{2}{*}{ Muslim } & 0.171 & -0.198 & -0.526 \\
\hline & $(0.415)$ & $(0.497)$ & $(0.637)$ \\
\hline \multirow[t]{2}{*}{ Muslim X NFS } & -0.590 & 0.218 & 0.922 \\
\hline & $(0.488)$ & $(0.649)$ & $(0.755)$ \\
\hline \multirow[t]{2}{*}{ Christian } & -0.836 & -0.807 & -0.932 \\
\hline & $(0.655)$ & $(0.860)$ & $(0.640)$ \\
\hline \multirow[t]{2}{*}{ Christian X Funct State } & 2.820 & 1.198 & 0.512 \\
\hline & $(2.000)$ & (1.930) & $(1.346)$ \\
\hline \multirow[t]{2}{*}{ Primary and below } & -0.043 & -0.268 & -0.313 \\
\hline & $(0.281)$ & $(0.282)$ & $(0.288)$ \\
\hline \multirow[t]{2}{*}{ Primary and below X NFS } & 0.235 & 0.031 & -0.005 \\
\hline & $(0.310)$ & $(0.342)$ & $(0.262)$ \\
\hline
\end{tabular}




\begin{tabular}{|c|c|c|c|}
\hline \multirow[b]{2}{*}{ Dep Var: Grain (rice + wheat) consumption from PDS } & \multicolumn{2}{|c|}{ Pooled 1} & \multirow{2}{*}{$\begin{array}{c}\text { Pooled } 2 \\
(3)\end{array}$} \\
\hline & (1) & $(2)$ & \\
\hline \multirow[t]{2}{*}{ Above primary } & $-0.943 * *$ & $-2.131 * * *$ & $-2.280 * * *$ \\
\hline & $(0.449)$ & (0.409) & $(0.394)$ \\
\hline \multirow[t]{2}{*}{ Above primary $X \mathrm{NFS}$} & $1.250 * * *$ & $1.174 * * *$ & $1.394 * * *$ \\
\hline & $(0.329)$ & $(0.381)$ & $(0.357)$ \\
\hline \multirow[t]{2}{*}{ Self Employed in Non Agri } & $-1.444 * *$ & $-2.445 * * *$ & $-2.323 * * *$ \\
\hline & $(0.558)$ & $(0.602)$ & $(0.597)$ \\
\hline \multirow[t]{2}{*}{ Self Employed in Non Agri X NFS } & $1.070^{*}$ & 0.245 & 0.110 \\
\hline & $(0.548)$ & $(0.608)$ & $(0.670)$ \\
\hline \multirow[t]{2}{*}{ Other Labour } & $-1.180 *$ & $-1.738 * * *$ & $-1.748 * * *$ \\
\hline & $(0.631)$ & $(0.576)$ & $(0.558)$ \\
\hline \multirow[t]{2}{*}{ Other Labour X NFS } & $1.087^{*}$ & 0.847 & $1.071 *$ \\
\hline & $(0.560)$ & $(0.677)$ & $(0.582)$ \\
\hline \multirow[t]{2}{*}{ Self Emp in Agriculture } & $-2.069 * * *$ & $-3.112 * * *$ & $-2.947 * * *$ \\
\hline & $(0.538)$ & $(0.661)$ & $(0.677)$ \\
\hline \multirow[t]{2}{*}{ Self Emp in Agriculture X NFS } & $1.511 * * *$ & -0.212 & -0.434 \\
\hline & $(0.542)$ & $(0.683)$ & $(0.707)$ \\
\hline \multirow[t]{2}{*}{ Other Occupation } & $-3.172 * * *$ & $-5.037 * * *$ & $-5.091 * * *$ \\
\hline & $(0.489)$ & $(0.432)$ & $(0.437)$ \\
\hline \multirow[t]{2}{*}{ Other Occupation X NFS } & $2.601 * * *$ & $1.531 * *$ & $1.791 * *$ \\
\hline & $(0.623)$ & $(0.668)$ & $(0.721)$ \\
\hline \multirow[t]{2}{*}{ Female Headed Household } & $-1.497^{* * *}$ & $-1.107 * * *$ & $-0.966 * *$ \\
\hline & $(0.309)$ & $(0.378)$ & $(0.446)$ \\
\hline \multirow[t]{2}{*}{ Female Headed Household X NFS } & $2.724 * * *$ & $3.018 * * *$ & $3.076 * * *$ \\
\hline & $(0.351)$ & $(0.338)$ & $(0.387)$ \\
\hline \multirow[t]{2}{*}{ Land operated } & -0.010 & -0.161 & -0.180 \\
\hline & $(0.101)$ & $(0.122)$ & $(0.121)$ \\
\hline \multirow[t]{2}{*}{ Land operated X NFS } & 0.035 & 0.036 & 0.097 \\
\hline & $(0.104)$ & (0.139) & $(0.141)$ \\
\hline \multirow[t]{2}{*}{ Household size } & $0.751 * * *$ & $0.764 * * *$ & $0.812 * * *$ \\
\hline & $(0.129)$ & $(0.140)$ & $(0.149)$ \\
\hline \multirow[t]{2}{*}{ Year $=2011 \times$ NFS } & 0.688 & 0.687 & 1.178 \\
\hline & $(1.282)$ & $(1.326)$ & (1.375) \\
\hline \multirow[t]{2}{*}{ Year $=2009 \times$ NFS } & & & -1.606 \\
\hline & & & $(1.088)$ \\
\hline R-squared & 0.466 & 0.278 & 0.282 \\
\hline $\mathrm{N}$ & 73263 & 83598 & 119114 \\
\hline
\end{tabular}

Note: pooled $1=2004$ and 2011; pooled $2=2004,2009$ and 2011. NFS = dummy variable (functioning state=0; 1 otherwise). Standard errors, clustered by state region, appear in parentheses below parameter estimates. Sampling weights have been used for all estimation. All specifications include state, state-region and year dummies. Statistical significance: ***=1 percent; $* *=5$ percent; ${ }^{*}=10$ percent. 
Table 5: Difference in PDS Consumption in Non-Functioning States

\begin{tabular}{lccc}
\hline \hline & Difference & F-Stat & p-value \\
\cline { 2 - 3 } Scheduled Tribe and Upper Caste & -1.337 & 4.760 & 0.035 \\
Scheduled Caste and Upper Caste & -0.186 & 0.226 & 0.637 \\
OBC and Upper Caste & -0.333 & 0.993 & 0.325 \\
& & 0.410 \\
Illiterate and Above Primary & 0.306 & 0.692 & 0.43 \\
Agricultural Labor and Self Employed in Non Agriculture & & 0.377 \\
Agricultural Labor and Other Labor & -0.374 & 0.797 & 0.870 \\
Agricultural Labor and Self Employed in Agriculture & -0.093 & 0.027 & 0.301 \\
Agricultural Labor and Professionals & -0.558 & 1.094 & 0.259 \\
\hline Female-Headed and Male-Headed & -0.571 & 1.307 & \\
\hline
\end{tabular}

Note: calculated from parameter estimates and standard errors for specification 1 in Table 4. 




Figure 1: Scatter plot of PDS consumption and diversion across 34 Indian states and union territories in 2011-2012. Diversion is defined as 100*(1-NSS Consumption/Offtake); Arunachal Pradesh has been excluded as an outlier. (Source: Table 1) 